\title{
Glycosylation at 11 Asn on hemagglutinin of H5N1 influenza virus contributes to its biological characteristics
}

\author{
Yuncong Yin 1,2,3, Xiaojian Zhang 1,2,3, Yiyi Qiao ${ }^{1,2,3}$, Xiao Wang 1,2,3, Yangyang Su 1,2,3, Sujuan Chen 1,2,3, Tao Qin ${ }^{1,2,3}$, \\ Daxin Peng ${ }^{1,2,3^{*}}$ (D) and Xiufan Liu ${ }^{1,2,3}$
}

\begin{abstract}
A stem glycosylation site of hemagglutinin $(\mathrm{HA})$ is important to the stability of the HA trimmer. A previous study shows that the stem 10/11 overlap glycosylation site of the H5 subtype avian influenza virus may influence the cleavage of $\mathrm{HA}$, whereas the exact site and its effect on virulence remain unclear. In this study, site-directed mutagenesis was used to generate single or double mutant rSY- $\triangle 10(10 N N A T)$, rSY- $\triangle 11$ (10NNSA), and rSY- $\triangle 10 / 11$ (10NNAA) of the overlapping glycosylation site (10NNST) on the HA of A/Mallard/Huadong/S/2005(SY). By using Western blot analysis, we show that both $r S Y-\triangle 11$ and $r S Y-\triangle 10 / 11$ mutant viruses had significant delay on $H A$ cleavage and a reduced $H A$ molecular mass compared to the wild-type virus rSY, while the rSY- $\triangle 10$ mutant virus exhibited a similar HA molecular mass to that of the wild-type virus rSY. Interestingly, both rSY- $\triangle 11$ and rSY- $\triangle 10 / 11$ mutant viruses reverted their glycosylation sites at $11 \mathrm{~N}$ after passage, indicating that $11 \mathrm{~N}$ is a true and critical glycosylation site. Compared to the wildtype virus rSY, rSY- $\triangle 11$ and rSY- $\triangle 10 / 11$ mutant viruses had decreased growth rates, reduced thermo- and pH-stability, decreased pathogenicity, and limited systemic spread. Therefore, our study suggests that the $11 \mathrm{~N}$ glycosylation site plays a key role in HA cleavage, structural stability and pathogenicity in $\mathrm{H} 5$ subtype avian influenza virus.
\end{abstract}

\section{Introduction}

H5 subtype avian influenza virus (AIV) infects not only poultry but also mammals worldwide [1-3], thus posing a threat to the poultry industry and to public health $[4,5]$. Hemagglutinin (HA), a surface glycoprotein, plays an important role in the influenza life cycle $[4,6]$. As the avian influenza virus evolves, glycosylation distribution of HA is becoming increasingly complicated $[7,8]$. Glycosylation sites function differently depending on their location: the glycan near the antigen epitope may cause immune escape by disturbing antibody recognition [9-11]; the glycan near the cleavage sites may result in virulence reduction due to HA cleavage deficiency $[12,13]$; the glycan near the receptor binding site may change its receptor affinity $[14,15]$. Stem glycosylation of

\footnotetext{
*Correspondence: pengdx@yzu.edu.cn

${ }^{1}$ College of Veterinary Medicine, Yangzhou University, Yangzhou 225009,

Jiangsu, China

Full list of author information is available at the end of the article
}

HA appears conserved, mainly attributed to the stability of the HA trimer $[14,16]$. A previous study shows that there is a potential $10 / 11$ glycosylation site overlap on the HA stem of the SY virus, which plays an important role in cleavage [17]. However, the exact glycosylation site remains unclear. In this study, site-direct mutagenesis was used to delete the overlapping glycosylation site, so biological characteristics of the mutants could be determined.

\section{Materials and methods}

All animal studies were approved by the Jiangsu Administrative Committee for Laboratory Animals (Permission Number: SYXKSU-2007-0005) and complied with the Guidelines of Laboratory Animal Welfare and Ethics of Jiangsu Administrative Committee for Laboratory Animals. 


\section{Viruses and cells}

Madin-Darby canine kidney (MDCK) cells, human embryonic (293T) cells and chicken embryo fibroblast (CEF) cells were maintained in Dubecco's modified Eagle's medium (DMEM) with 10\% fetal bovine serum (FBS, Foundation, Gemini) at $37{ }^{\circ} \mathrm{C}$ with $5 \% \mathrm{CO} 2$. AIV A/Mallard/Huadong/S/2005 (SY, H5N1) [18] was propagated in 10-day-old specific-pathogen-free (SPF) embryonic chicken eggs.

\section{Site-directed mutagenesis, virus rescue and identification}

Site-directed mutagenesis of the HA gene of the H5N1 AIV SY strain was performed by overlap-PCR with the primers indicated in Table 1 . To delete $\mathrm{N}$-glycosylation sites at $10 / 11 \mathrm{NN}, 12 \mathrm{Ser}$ and $13 \mathrm{Thr}$ were substituted separately or simultaneously with Ala. The modified HA genes were cloned to the pHW2000 vector and confirmed by sequencing [19]. Then, the eight rescue plasmids with or without mutant HA plasmids were co-transfected into a mixture of 293T and MDCK cells using polyjet (SignalGen). The culture mixtures were treated with repeated freeze-thaw at $48 \mathrm{~h}$ post-transfection and then inoculated into 10-day-old SPF eggs for amplification of rescue viruses at $37{ }^{\circ} \mathrm{C}$. All rescue viruses were then tested individually for the presence of infectious viruses through a standard hemagglutination assay by $1 \%$ chicken red blood cells. The RNA of the rescue viruses were extracted by Trizol (Invitrogen) and amplified by RT-PCR. All viral gene segments were sequenced to ensure the absence of unwanted mutations. Each rescue virus was passaged at least five generations in SPF eggs or chicken embryo cells. To measure the virus titer, the individual virus was serially diluted tenfold from $10^{-1}$ to $10^{-9}$, and each dilution $\left(10^{-5}-10^{-9}\right)$ was inoculated into four 10-day-old SPF eggs or CEF cells. The $50 \%$ chicken embryo infection dose $\left(\mathrm{EID}_{50} / \mathrm{mL}\right)$ and $50 \%$ tissue culture infection dose $\left(\mathrm{TCID}_{50} / \mathrm{mL}\right)$ were calculated as previously described [20].

\section{Western blot analysis}

To analyze the molecular mass of HA protein in the viruses [21], CEF cells were inoculated with the recombinant viruses at a multiplicity of infection (MOI) of 1 and incubated for $1 \mathrm{~h}$ at $37^{\circ} \mathrm{C}$ with $5 \% \mathrm{CO} 2$. The infected cells were washed three times with PBS and then fresh DMEM containing 2\% FBS was added. At $12 \mathrm{~h}$ incubation, the cells were washed with pre-cooled PBS, scraped and lysed with $200 \mu \mathrm{L}$ of lysis buffer (Thermofisher Scientific) individually on ice for $15 \mathrm{~min}$. Total proteins were collected by centrifugation at $13000 \mathrm{rpm}$ at $4{ }^{\circ} \mathrm{C}$ for $10 \mathrm{~min}$, subjected to $12 \%$ SDS-PAGE, and transferred to PVDF membrane. The membrane was blocked in 5\% skimmed milk, incubated with mAb SYA9 and polyAb anti-M mouse serum, and then incubated with horseradish
Table 1 Mutagenesis primers for the hemagglutinin gene

\begin{tabular}{lll}
\hline Mutation & Direction & Primer sequence $\mathbf{( 5}^{\prime} \mathbf{- \mathbf { 3 } ^ { \prime } \mathbf { ) }}$ \\
\hline SYS10A & Forward & CATGCAAACAACGCGACAGA \\
& Reverse & TCTGTCGCGTTGTTTGCATG \\
SYT11A & Forward & CATGCAAACAACTCGGCAGA \\
& Reverse & TCTGCCGAGTTGTTTGCATG \\
SY ST10/11AA & Forward & CATGCAAACAACGCGGCAGA \\
& Reverse & TCTGCCGCGTTGTTTGCATG \\
\hline
\end{tabular}

The substitution nucleotides are underlined.

peroxidase-conjugated goat anti-mouse antibodies. The protein bands were developed using a chemiluminescence imaging analysis system. For time-point analysis, the CEF monolayer cells infected with each recombinant virus was taken at $12 \mathrm{~h}$ intervals from 12 to $72 \mathrm{~h}$ postinfection (hpi) and frozen in $-80{ }^{\circ} \mathrm{C}$. All collected cells were subjected to Western blot analysis.

\section{Virus growth}

Monolayer CEF cells were infected with each recombinant virus at an MOI of 1 in DMEM for $1 \mathrm{~h}$. Then cells were washed to remove unbound viruses and fresh DMEM was added. The cells were incubated at $37{ }^{\circ} \mathrm{C}$ with $5 \% \mathrm{CO}_{2}$ and supernatants were sampled every $12 \mathrm{~h}$. After $72 \mathrm{hpi}$, $\mathrm{TCID}_{50}$ on CEF cells were determined for all samples [22].

\section{Thermostability}

Recombinant viruses were divided into nine $60 \mu \mathrm{L}$ aliquots. All aliquots were exposed to $56{ }^{\circ} \mathrm{C}$ and each recombinant group was quickly cooled to $4{ }^{\circ} \mathrm{C}$ after 0 , $5,10,15,30,60,90,120$ and $150 \mathrm{~min}$ incubation [23]. The titers of all aliquots were then tested by standard hemagglutination assay with $1 \%$ chicken red blood cells. All recombinant viruses were also diluted to the same $\mathrm{TCID}_{50}$ and incubated at 37 or $42{ }^{\circ} \mathrm{C}$ for 1,3 and 5 days. The titers of all aliquots were tested by $\mathrm{TCID}_{50}$. In addition, methanol-inactivated recombinant viruses were incubated at 37 or $42{ }^{\circ} \mathrm{C}$ at a 2 -h interval for $18 \mathrm{~h}$. The titers of all samples were determined by hemagglutination assay.

\section{pH stability}

Recombinant viruses were mixed with an equal volume of $100 \mathrm{mM}$ acetate buffer $(\mathrm{pH}=4.0$ and $\mathrm{pH}=5.0)$, $100 \mathrm{mM}$ phosphate buffer $(\mathrm{pH}=6.0)$, or neutral phosphate buffer $(\mathrm{pH}=7.0)$ [24]. After a 10-min incubation at $37{ }^{\circ} \mathrm{C}$, the titers of all samples were determined by hemagglutination assay.

\section{IVPI determination in chickens}

Six-week-old SPF white leghorn chickens (10 per group) were injected intravenously with $0.1 \mathrm{~mL}$ of $1: 10$ diluted 
recombinant virus. Chickens were monitored daily for clinical signs of disease for 10 days, and the intravenous pathogenicity indices (IVPI) were calculated according to the OIE recommendation.

\section{Virulence determination in mice}

Eight-week-old BALB/c mice (5 per group) were infected intranasally with $10^{4}$ or $10^{6} \mathrm{EID}_{50}$ of each virus in $50 \mu \mathrm{L}$ PBS. The mice were weighed individually and monitored for signs of illness and mortality for 2 weeks. In addition, 8 -week-old mice (6 per group) were infected intranasally with $10^{4} \mathrm{EID}_{50}$ of each virus in $50 \mu \mathrm{L}$ PBS. Three mice from each group were euthanized on days 3 and 6 post-infection, and the lungs, brains, kidneys, spleens, hearts and livers were collected for virus titration [25-27].

\section{Statistical analysis}

The viral titers and antibody titers are expressed as the mean \pm standard deviation. Statistical analyses were performed using a Mann-Whitney test. Differences with a $p$ value of less than 0.05 were regarded to be statistically significant.

\section{Results}

\section{Rescue of the mutant viruses}

The overlapping glycosylation site at 10/11 in HA was modified by changing the rSY amino acid sequence NNST to NNAT, NNSA or NNAA, and the respective mutants were named rSY- $\Delta 10$, rSY- $\Delta 11$ and rSY- $\Delta 10 / 11$. All rescued viruses were confirmed by sequence analysis and were without spontaneous mutations in the first generation. However, after passage in SPF chicken embryonic egg or CEF for three generations, rSY- $\Delta 11$ reverted from NNSA to NNST and rSY- $\Delta 10 / 11$ from NNAA to NNAT, while no reversion was found for NNAT in rSY$\Delta 10$. Thus, all mutant viruses of the first generations were used for further experimentation except when indicated.

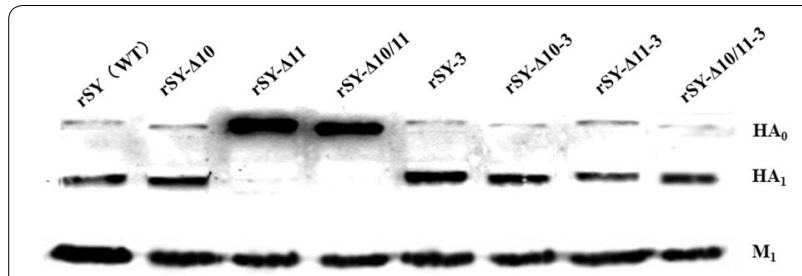

Figure 1 Western blot analysis of $\mathrm{HA}_{1}$ protein from recombinant virus. Lysates of CEF infected with $\mathrm{H} 5 \mathrm{~N} 1$ viruses at an $\mathrm{MOI}$ of 1 for $12 \mathrm{~h}$ were incubated with mAb SYA9 (anti-HA1 of H5N1) and mouse serum (anti-M1 of H5N1). The bands were visualized by a chemiluminescence imaging analysis system after incubation with peroxidase-conjugated secondary antibodies.

\section{Western blot analysis}

Western blot was used to determine whether the glycosylation site was removed from HA stem protein. As shown in Figure $1, \mathrm{M}_{1}$ proteins were expressed equally in all mutant viruses as well as in wild-type virus rSY, while $\mathrm{HA}_{1}$ from the mutant virus rSY- $\Delta 10$ showed a similar molecular mass to that of rSY at $12 \mathrm{hpi}$.
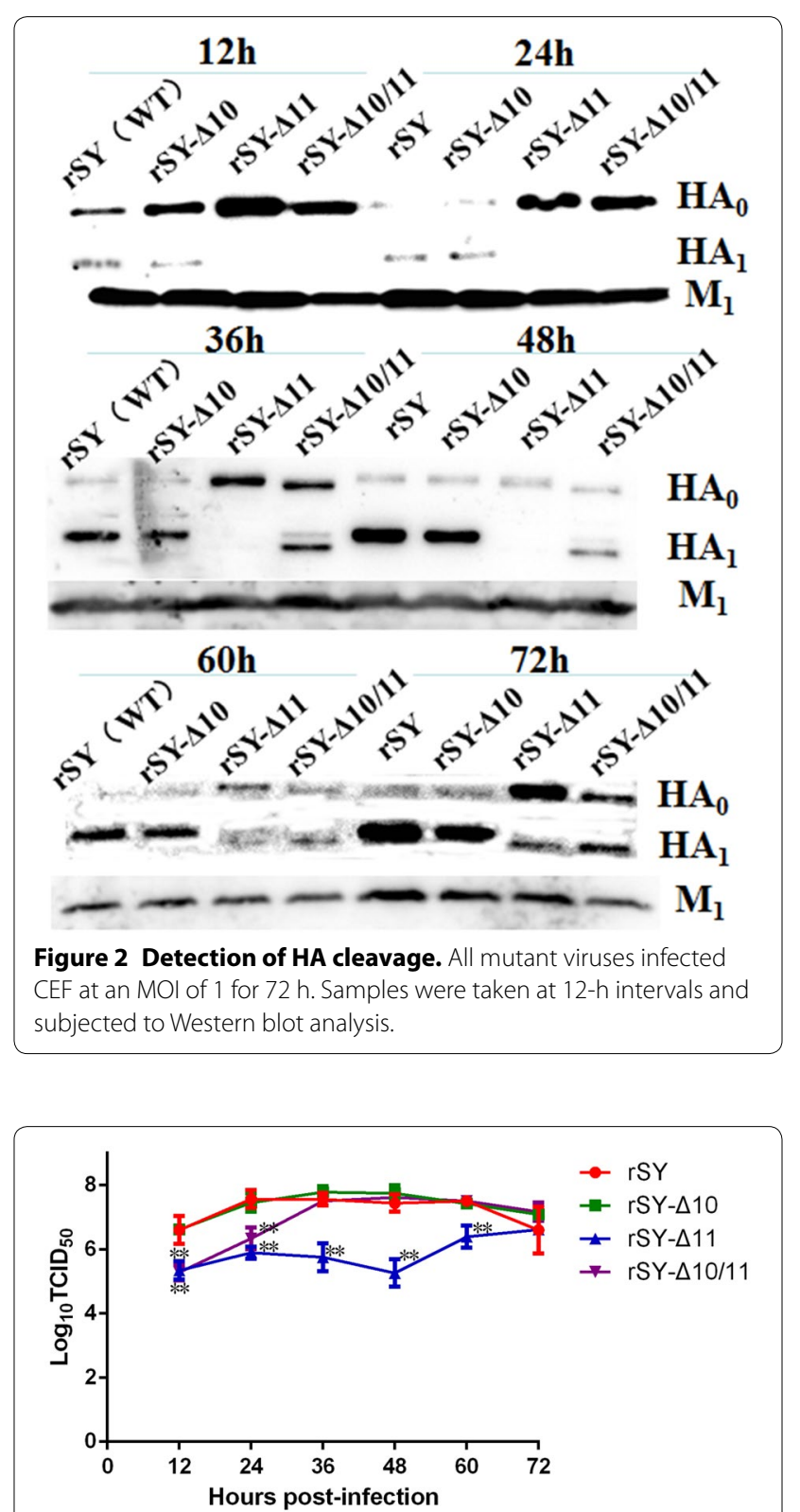

Figure 3 Growth curve of mutant virus in CEF. The cell monolayers were infected with mutant viruses at an $\mathrm{MOI}$ of 1 for $72 \mathrm{~h}$, and $\mathrm{TCID}_{50}$ virus titers were measured in the supernatants at the time points indicated. The error bars represent SD of the means from three independent experiments. The statistical differences in the growth properties between the wild-type virus and mutant viruses was assessed through a Mann-Whitney test $\left({ }^{*} p<0.05\right)$. 

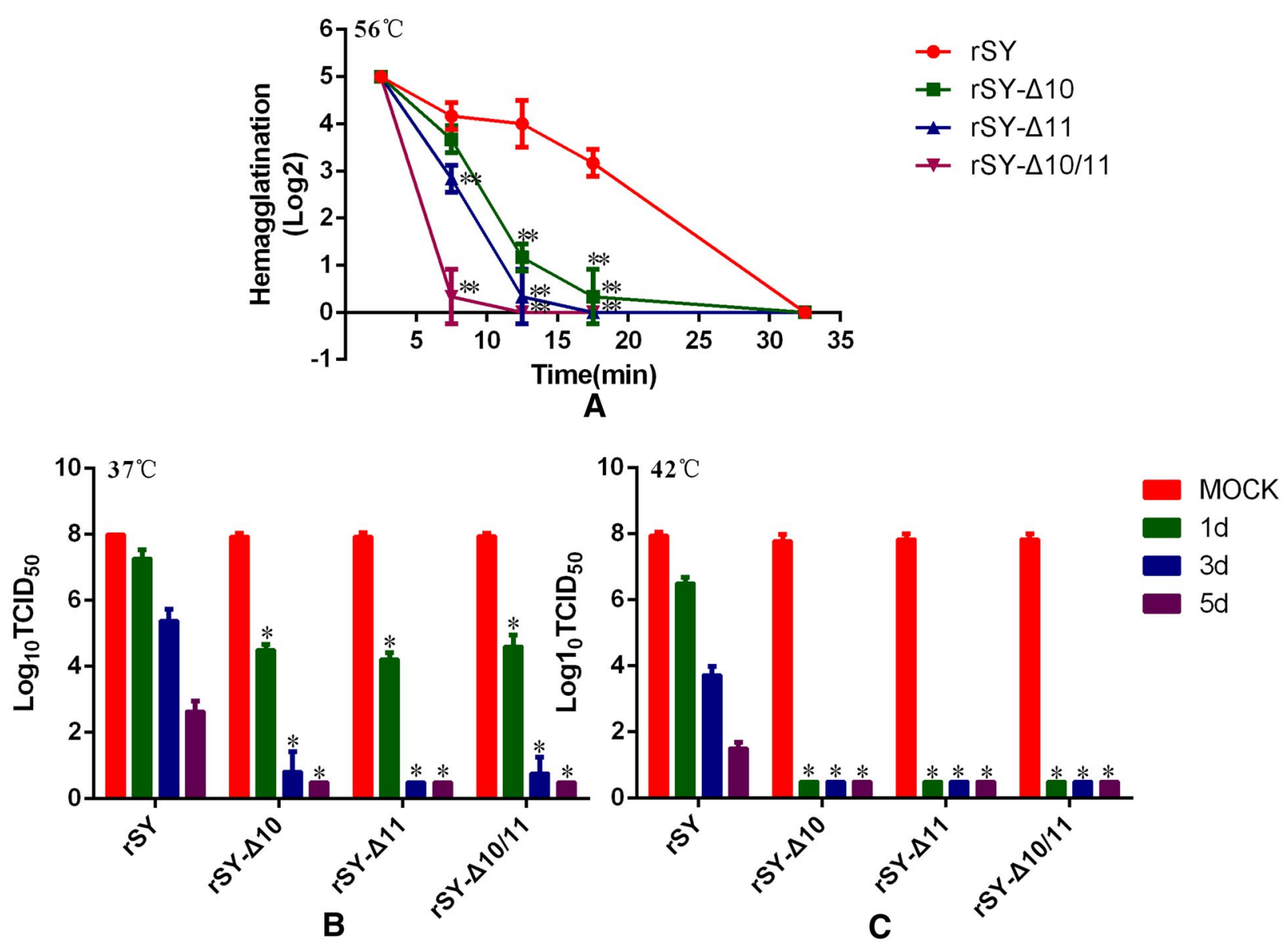

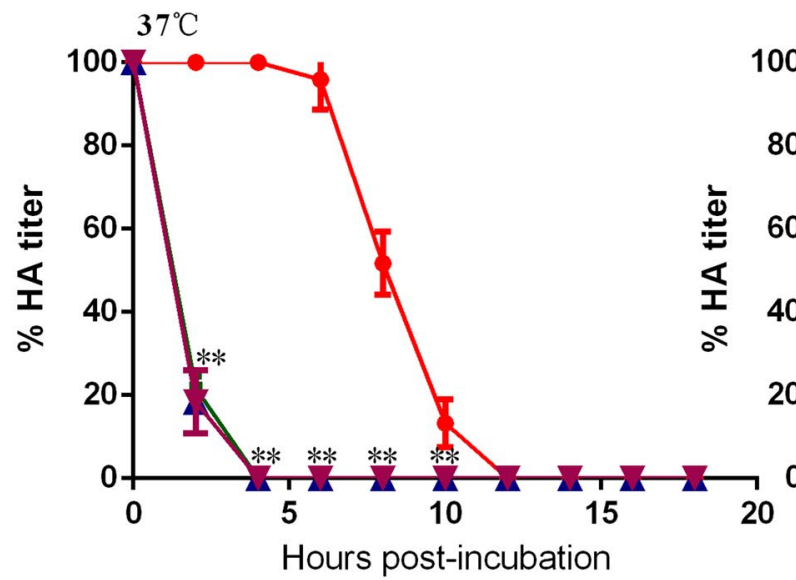

D
0

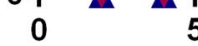

Hours post-incubation

E

Figure 4 Thermal stability of the mutant viruses. A Nine $60-\mu \mathrm{L}$ aliquots of mutant viruses were exposed to $56^{\circ} \mathrm{C}$ for 150 min. All aliquots were tested by hemagglutination assay. The error bars denote SD of the mean of three independent titers at each time point. B, C The wild-type virus and mutant viruses were incubated at $37^{\circ} \mathrm{C}(\mathbf{B})$ or $42^{\circ} \mathrm{C}(\mathbf{C})$ for 5 days. The $T C I D_{50}$ titers of the aliquots were determined in CEF cells. D, E The wild-type virus and mutant viruses were diluted to the same $\mathrm{TCID}_{50}$ and inactivated by methanol. Then all viruses were exposed to $37^{\circ} \mathrm{C}(\mathbf{D})$ or $42^{\circ} \mathrm{C}(\mathbf{E})$ for $18 \mathrm{~h}$ and every aliquot was collected every $2 \mathrm{~h}$. The titers of the aliquots were determined by hemagglutination assay. An asterisk indicates that the titer of the mutant virus was significantly different from those of the wild-type virus at the time points indicated, as determined by the Mann-Whitney test $\left({ }^{*} p<0.05,{ }^{* *} p<0.01\right)$. 
However, $\mathrm{HA}_{1}$ proteins from the mutant viruses rSY$\Delta 11$ or $\mathrm{rSY}-\Delta 10 / 11$ were not detectable, indicating $\mathrm{HA}_{0}$ was not lysed at that time. After the third passage, $\mathrm{HA}_{1}$ proteins from the mutant viruses of $\mathrm{rSY}-\Delta 11-3$ or rSY- $\Delta 10 / 11-3$ revealed similar molecular masses to that from the rSY, indicating that both mutant viruses rSY- $\Delta 11$ and $r S Y-\Delta 10 / 11$ recovered cleavage activity of $\mathrm{HA}_{0}$.

Next, $\mathrm{HA}_{1}$ proteins were detected at different time points (Figure 2). $\mathrm{HA}_{1}$ proteins from the rSY and rSY$\Delta 10$ viruses could be detected as early as $12 \mathrm{hpi}, \mathrm{HA}_{1}$ protein from the rSY- $\Delta 10 / 11$ could be detected from $36 \mathrm{hpi}$, and $\mathrm{HA}_{1}$ protein from the rSY- $\Delta 11$ could be detected from $60 \mathrm{hpi}$. $\mathrm{HA}_{1}$ protein from mutant viruses rSY- $\Delta 11$ and $r S Y-\Delta 10 / 11$ both showed reduced molecular masses compared to the rSY and rSY- $\Delta 10$ viruses. These data suggest that $11 \mathrm{~N}$ is the real glycosylation site and its loss may hinder HA protein cleavage in $\mathrm{H} 5 \mathrm{~N} 1$ AIV.

\section{Virus growth}

Chicken embryo fibroblast was inoculated with the mutant viruses at an MOI of 1 to determine whether glycosylation site removal would affect virus infection (Figure 3 ). Compared to wild-type virus rSY, rSY- $\Delta 10$ showed the same infectivity and growth tendency. However, the titer of rSY- $\Delta 10 / 11$ was significantly lower than that of rSY within $24 \mathrm{hpi}$ and was similar to that of rSY at $36 \mathrm{hpi}$. The titer of rSY- $\Delta 11$ was significantly lower than that of rSY up to $60 \mathrm{hpi}$. These data suggest that the $11 \mathrm{~N}$ glycosylation site deletion may result in low infectivity of H5N1 AIV in CEF.

\section{Thermal stability of the recombinant viruses}

All mutant viruses were treated with three temperatures $\left(56,42,37^{\circ} \mathrm{C}\right.$ ) to measure their thermal stability (Figure 4). All mutant viruses lost their hemagglutination within $20 \mathrm{~min}$ after $56^{\circ} \mathrm{C}$ incubation, while hemagglutination titer of the wild-type virus $\mathrm{rSY}$ remained $3 \log 2$ (Figure 4A). All live mutant viruses as well as inactivated mutant viruses showed the decreased thermal stability after 37 and $42{ }^{\circ} \mathrm{C}$ treatment, when compared to the wild-type virus rSY (Figures 4B-E).

\section{$\mathrm{pH}$ stability of the recombinant viruses}

All mutant viruses were exposed to low $\mathrm{pH}(\mathrm{pH}=4,5$, or 6) to assess their $\mathrm{pH}$ stability. The hemagglutination titer of wild-type virus rSY was unchanged when exposed to a $\mathrm{pH}$ of 6 or 5 . By contrast, the hemagglutination titers of all mutant viruses decreased significantly compared to that of the wild-type virus. All mutant and wild-type viruses lost their hemagglutination when treated with $\mathrm{pH}=4$ (Figure 5).

\section{Pathogenicity in chickens}

IVPI was used to measure the virulence of four mutant viruses in chickens (Table 2). Chickens injected with rSY and $\mathrm{rSY}-\Delta 10$ all died within 1 day. The IVPI were up to three in these two groups. Some of the chickens in the $\mathrm{rSY}-\Delta 11$ and $r S Y-\Delta 10 / 11$ groups died 1 day later and their IVPI were 2.89 and 2.86 , respectively. These data suggest that modification of $11 \mathrm{~N}$-glycosylation may decrease viral virulence in chickens, but the mutant viruses $r S Y-\Delta 11$ and $r S Y-\Delta 10 / 11$ were still highly pathogenic to chickens.

\section{Pathogenicity in mice}

To compare the virulence of mutant viruses in mice, 6-week-BALB/c mice were injected intranasally with a dose of $10^{4} \mathrm{EID}_{50}$ and $10^{6} \mathrm{EID}_{50}$ of each mutant virus. With $10^{6}$ EID $_{50}$ infection dosage (Figures $6 \mathrm{~A}$ and $\mathrm{B}$ ), the viruses $r S Y$ and $r S Y-\Delta 10$ caused a large decrease in mice body weight and all mice were dead within 7 days.

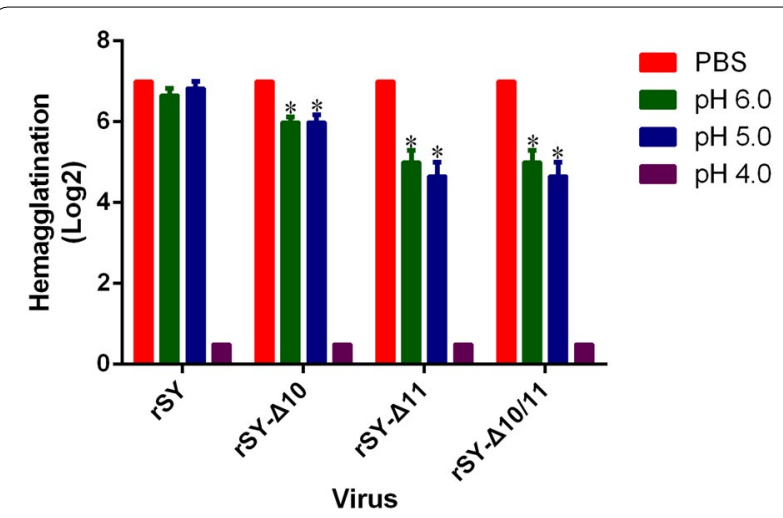

Figure $5 \mathrm{pH}$ stability of the recombinant virus. The recombinant viruses were incubated in each buffer at $37^{\circ} \mathrm{C}$ for $10 \mathrm{~min}$, and the viral titers were determined by hemagglutination assay. The results are presented as $\log 2 \mathrm{HA}$ titers at the indicated $\mathrm{pH}$ conditions. The error bars denote SD of the mean of three independent titers at each time point. The statistical significance of the differences in $\mathrm{pH}$ stability between the wild-type virus and mutant viruses was assessed through the Mann-Whitney test $\left({ }^{*} p<0.05\right)$.

Table 2 Determination of intravenous pathogenicity indexes for the mutant viruses

\begin{tabular}{ll}
\hline Recombinant virus & IVPIs \\
\hline SY (wild-type) & 3 \\
rSY- $\triangle 10$ & 3 \\
rSY- $\triangle 11$ & 2.89 \\
rSY- $\triangle 10 / 11$ & 2.86 \\
\hline
\end{tabular}

6-week-old SPF white leghorn chickens (10 chickens per group) were inoculated intravenously with $0.1 \mathrm{~mL}$ of 1:10 dilution of allantoic fluid containing each virus. Experimental SPF chickens were monitored daily for clinical signs of disease for 10 days, and the intravenous pathogenicity indexes (IVPI) were calculated according to the recommendation of the OIE. 


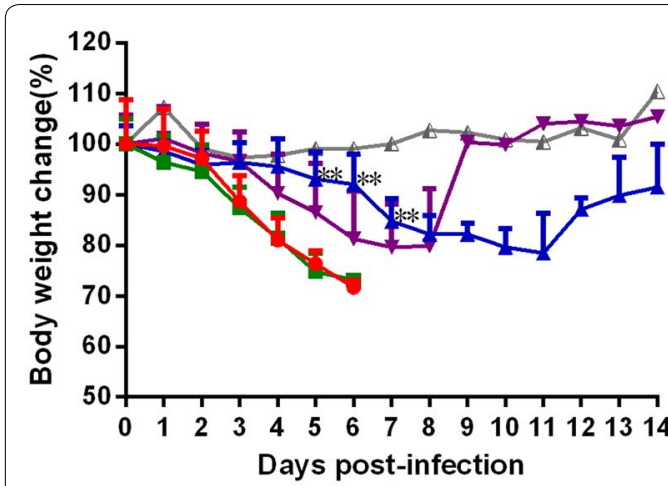

A

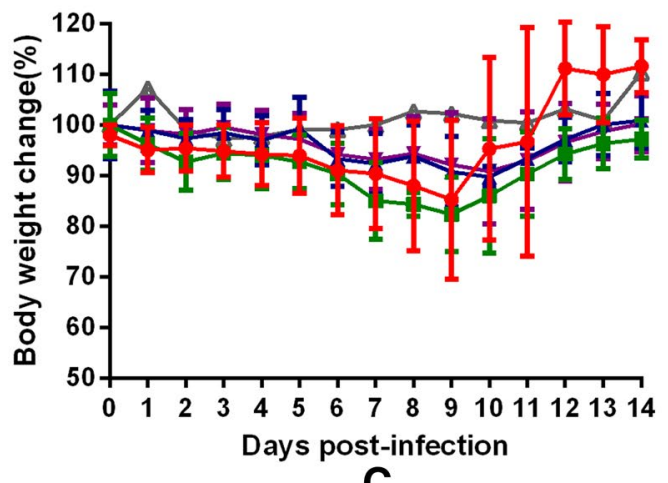

C

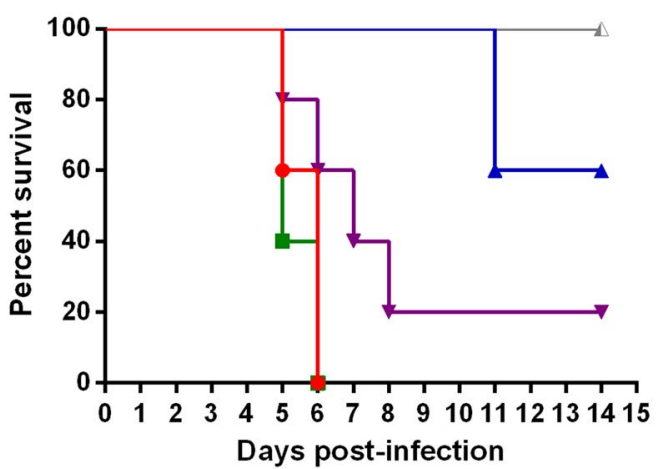

B

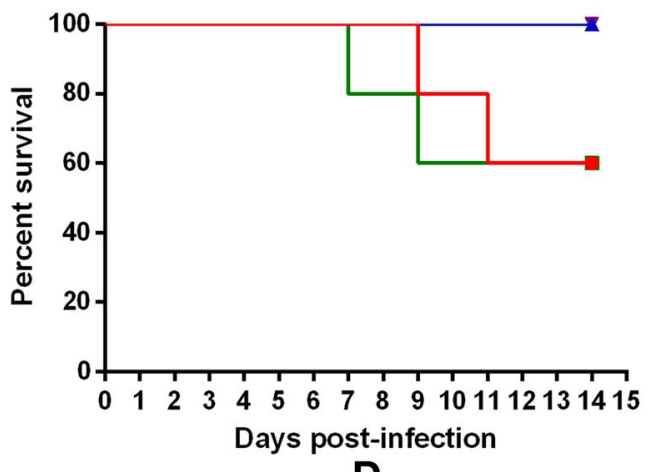

$\rightarrow r S Y$

$=r S Y-\Delta 10$

\pm rSY $-\Delta 11$

$\rightarrow$ rSY $-\Delta 10 / 11$

$\leftarrow$ PBS

Figure 6 Pathogenicity of mutant viruses in mice. Groups of 5 mice were infected intranasally with $10^{6} \mathrm{EID}_{50}(\mathbf{A}, \mathbf{B})$ and $10^{4} \mathrm{EID} \mathrm{D}_{50}(\mathbf{C}, \mathbf{D})$ of mutant viruses. Mice were monitored daily for weight loss and signs of disease over a 14-day period. Data represents the mean body weight change $(\%) \pm$ SD. Statistical analysis between the wild-type virus and the mutant viruses was performed using Mann-Whitney test (** $p<0.01$ ).

Meanwhile, the rSY- $\Delta 11$ and $\mathrm{rSY}-\Delta 10 / 11$ viruses caused less decline in body weight and resulted in 60 and $20 \%$ survival, respectively. With a $10^{4} \mathrm{EID}_{50}$ infection dosage (Figures $6 \mathrm{C}$ and $\mathrm{D}$ ), mice in $\mathrm{rSY}$ and rSY- $\Delta 10$ groups had $60 \%$ survival, while all mice in rSY- $\Delta 11$ and rSY- $\Delta 10 / 11$ groups survived. Dead or euthanized mice at the end of the experiment were taken for virus isolation, and sequencing confirmed that no reversion or unwanted mutation occurred in the isolated viruses.

To further understand the effect of the glycosylation site on virulence in mice. The mice were infected with $10^{4}$ EID $_{50}$ of each virus. As shown in Table 3, the rSY and $\mathrm{rSY}-\Delta 10$ viruses replicated efficiently in the lungs on days 3 and 6 post-infection, and replicated less in other organs. By contrast, rSY- $\Delta 10 / 11$ and rSY- $\Delta 11$ viruses replicated less efficiently, with the former only being weakly detected in the lungs on day 3 post-infection and the latter absent in any organ on either days 3 and 6 postinfection. These data suggest that the $11 \mathrm{~N}$ glycosylation site deletion leads to reduced virulence in mice.

\section{Discussion}

There are a variety of potential glycosylation sites distributed among SY-H5N1 subtype AIV hemagglutinin. Among them, 10/11NNST is highly conserved. A previous study showed that $10 / 11$ NNST is an overlapping glycosylation site, the double deletion of which hinders $\mathrm{HA}_{0}$ cleavage [17], and that $10 \mathrm{~N}$ might be a real glycosylation site based on Western blot analysis of viruses mutated from NNST to NPST and NNAA. In this study, three mutant viruses were constructed to delete the $10 \mathrm{~N}, 11 \mathrm{~N}$ and $10 / 11 \mathrm{NN}$ glycosylation site by substituting NNST with NNAT, NNSA and NNAA, respectively. Although all rescued viruses were confirmed by sequence analysis and were without spontaneous mutations in the first generation, Western blot analysis showed that $\mathrm{HA}_{1}$ patterns from the first generations of mutant viruses $\mathrm{rSY}-\Delta 11$ or rSY- $\Delta 10 / 11$ were not consistent with that from their fifth generation viruses. Further sequence analysis of each generation of the mutant viruses revealed that, since the mutants $\mathrm{rSY}-\Delta 11$ or $\mathrm{rSY}-\Delta 10 / 11$ were passaged in chicken embryonic egg or CEF for three generations, the NNSA or NNAA sequences of mutant viruses had been reverted to NNST or NNAT, respectively, which allowed 


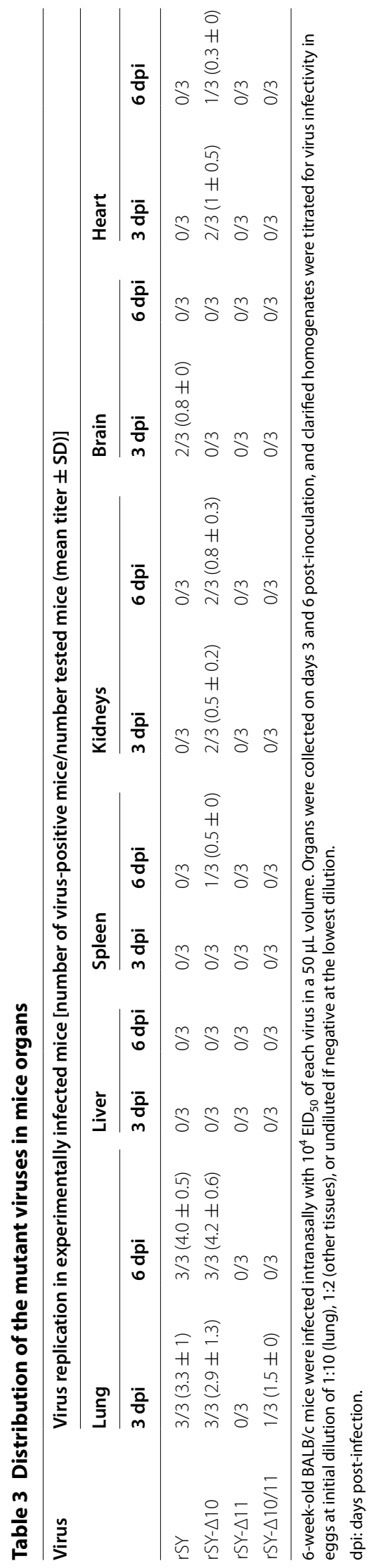


the mutant viruses to form a glycosylation site at $11 \mathrm{~N}$ again. In a previous study, the fifth generations of mutant viruses (NPST, NNSA, NNAA) were used to determine the $\mathrm{HA}_{1}$ patterns by Western blot analysis, this may be the reason that the reverted viruses were used and no change was found between the $11 \mathrm{~N}$ mutant (NNSA) and the wild-type virus rSY [17]. Since the deletion of $11 \mathrm{~N}$ glycosylation site reverted quickly, the H5 subtype influenza virus survival may depend on this glycosylation site. This may explain why this overlapping glycosylation site is highly conserved. Our Western blot analysis shows that once the 11-glycosylation site was removed, $\mathrm{HA}_{0}$ cleavage was hindered. Only $\mathrm{HA}_{0}$ was detectable at the beginning, but this cleavage of $\mathrm{HA}_{0}$ still happened during late infection, which resulted in a low virus titer in the early stage of infection in CEF. Also, we found that $\mathrm{HA}_{0}$ cleavage correlated with virus growth. When $\mathrm{HA}_{0}$ can be cleaved, the virus titer is relative high. We also found that the molecular masses of $\mathrm{HA}_{1}$ from the mutant viruses rSY- $\Delta 11$ and $r S Y-\Delta 10 / 11$ were lower than that of the mutant virus rSY- $\Delta 10$ and the wild-type virus rSY. These data indicate that $11 \mathrm{~N}$, rather than $10 \mathrm{~N}$, is the real glycosylation site, which was consistent with other studies suggesting that NST is more likely to form a glycosylation site among NNST combination [12, 28-30]. We also speculated that steric hindrance may be the main cause of cleavage delay in rSY- $\Delta 11$ and $r S Y-\Delta 10 / 11$, but this hypothesis remains to be tested.

One of the main functions of stem glycosylation sites is to maintain the structural stability of the virus. Thus, disrupted viral stability due to glycosylation site removal likely accounted for heat and $\mathrm{pH}$ sensitivity in $\mathrm{rSY}-\Delta 11$ and rSY- $\Delta 10 / 11$. However, if $10 \mathrm{~N}$ could not form a glycosylation site, why is rSY- $\Delta 10$ still unstable? It is generally believed that the $\mathrm{N}$-glycosylation site has a fixed amino acid sequence motif: NXS/T $(X\langle>P)$. Different X in NXS/T may have different glycosylation stability. In this study, substituting NNST with NNAT did not affect the $10 \mathrm{~N}$-glycosylation since $10 \mathrm{~N}$ is not a glycosylation site, while substituting NST with NAT may affect the $11 \mathrm{~N}$ glycosylation site [30] or changed the HA structure, which also resulted in lower stability of virus to heat and low-pH.

Head glycosylation of HA may contribute to virulence and antigenicity of influenza viruses, and influenza viruses have variety patterns of head glycosylation [31-34]. However, the role of overlapping stem glycosylation on virulence remains unknown. Although the IPVI of mutant viruses rSY- $\Delta 11$ and $r S Y-\Delta 10 / 11$ in chickens were lower than that of mutant virus rSY- $\Delta 10$ and rSY, both mutant viruses were still highly pathogenic to chickens. In mice, rSY- $\Delta 11$ and rSY- $\Delta 10 / 11$ mutants showed a significant reduction in virulence compared to wild-type virus rSY and mutant virus rSY- $\Delta 10$, presenting a relative limited and low-titer virus distribution among organs, less body weight loss, and lower mortality. The attenuation of virulence of the mutant viruses in chickens and mice may be attributable to the delay of $\mathrm{HA}_{0}$ cleavage [8].

In conclusion, we successfully rescued three modified viruses at the overlapping glycosylation site in the stem of HA, and found that the $11 \mathrm{~N}$ glycosylation site of SY H5N1 virus was the true glycosylation site, which was critical for HA cleavage and viral virulence. This study facilitates an improved understanding of the role of overlapping glycosylation sites.

Competing interests

The authors declare that they have no competing interests.

\section{Authors' contributions}

$D P$ and $Y Y$ participated in the design of the study. $Y Y, X Z, Y Q, X W$ performed the experiment. YS, SC, and TQ analyzed the data and drafted the manuscript. DP and XL planned the experiments and helped write the manuscript. All authors read and approved the final manuscript.

\section{Acknowledgements}

This study was partially supported by the Important National Science \& Technology Specific Projects (2016YFD0500202), the National Natural Science Foundation of China (Nos. 31372450, 31402229), the Agricultural Science \& Technology Independent Innovation Fund of Jiangsu Province [CX(15)1065], and a Project Funded by the Priority Academic Program Development of Jiangsu Higher Education Institutions.

\section{Author details \\ ${ }^{1}$ College of Veterinary Medicine, Yangzhou University, Yangzhou 225009, Jiangsu, China. ${ }^{2}$ Jiangsu Co-Innovation Center for the Prevention and Control of Important Animal Infectious Disease and Zoonoses, Yangzhou 225009, Jiangsu, China. ${ }^{3}$ Jiangsu Research Centre of Engineering and Technology for Prevention and Control of Poultry Disease, Yangzhou 225009, Jiangsu, China.}

\section{Publisher's Note}

Springer Nature remains neutral with regard to jurisdictional claims in published maps and institutional affiliations.

Received: 24 June 2017 Accepted: 9 October 2017

Published online: 21 November 2017

\section{References}

1. Chang H, Dai F, Liu Z, Yuan F, Zhao S, Xiang X, Zou F, Zeng B, Fan Y, Duan G (2014) Seroprevalence survey of avian influenza A (H5) in wild migratory birds in Yunnan Province, Southwestern China. Virol J 11:18

2. Dung TC, Dinh PN, Nam VS, Tan LM, Hang Nle K, le Thanh T, le Mai Q (2014) Seroprevalence survey of avian influenza A(H5N1) among live poultry market workers in northern Viet Nam, 2011. Western Pac Surveill Response J 5:21-26

3. Smith GJ, Donis RO, World Health Organization/World Organisation for Animal Health/Food and Agriculture Organization (WHO/OIE/FAO) H5 Evolution Working Group (2015) Nomenclature updates resulting from the evolution of avian influenza $\mathrm{A}(\mathrm{H} 5)$ virus clades 2.1.3.2a, 2.2.1, and 2.3.4 during 2013-2014. Influenza Other Respir Viruses 9:271-276

4. Webster RG, Bean WJ, Gorman OT, Chambers TM, Kawaoka Y (1992) Evolution and ecology of influenza A viruses. Microbiol Rev 56:152-179

5. World Health Organization/World Organisation for Animal Health/Food and Agriculture Organization (WHO/OIE/FAO) H5N1 Evolution Working Group (2014) Revised and updated nomenclature for highly pathogenic avian influenza A (H5N1) viruses. Influenza Other Respir Viruses 8:384-388 
6. Urbaniak K, Markowska-Daniel I (2014) In vivo reassortment of influenza viruses. Acta Biochim Pol 61:427-431

7. Chen W, Zhong Y, Qin Y, Sun S, Li Z (2012) The evolutionary pattern of glycosylation sites in influenza virus (H5N1) hemagglutinin and neuraminidase. PLoS One 7:e49224

8. Matsuoka Y, Matsumae H, Katoh M, Eisfeld AJ, Neumann G, Hase T, Ghosh S, Shoemaker JE, Lopes TJ, Watanabe T, Watanabe S, Fukuyama S, Kitano $H$, Kawaoka Y (2013) A comprehensive map of the influenza A virus replication cycle. BMC Syst Biol 7:97

9. Wang CC, Chen JR, Tseng YC, Hsu CH, Hung YF, Chen SW, Chen CM, Khoo KH, Cheng TJ, Cheng YS, Jan JT, Wu CY, Ma C, Wong CH (2009) Glycans on influenza hemagglutinin affect receptor binding and immune response. Proc Natl Acad Sci U S A 106:18137-18142

10. Wang TT, Tan GS, Hai R, Pica N, Petersen E, Moran TM, Palese P (2010) Broadly protective monoclonal antibodies against $\mathrm{H} 3$ influenza viruses following sequential immunization with different hemagglutinins. PLoS Pathog 6:e1000796

11. Skehel JJ, Stevens DJ, Daniels RS, Douglas AR, Knossow M, Wilson IA Wiley DC (1984) A carbohydrate side chain on hemagglutinins of Hong Kong influenza viruses inhibits recognition by a monoclonal antibody. Proc Natl Acad Sci U S A 81:1779-1783

12. Deshpande KL, Fried VA, Ando M, Webster RG (1987) Glycosylation affects cleavage of an $\mathrm{H} 5 \mathrm{~N} 2$ influenza virus hemagglutinin and regulates virulence. Proc Natl Acad Sci U S A 84:36-40

13. Kawaoka Y, Webster RG (1989) Interplay between carbohydrate in the stalk and the length of the connecting peptide determines the cleavability of influenza virus hemagglutinin. J Virol 63:3296-3300

14. Liao HY, Hsu CH, Wang SC, Liang CH, Yen HY, Su CY, Chen CH, Jan JT, Ren CT, Chen CH, Cheng TJ, Wu CY, Wong CH (2010) Differential receptor binding affinities of influenza hemagglutinins on glycan arrays. J Am Chem Soc 132:14849-14856

15. Matrosovich M, Zhou N, Kawaoka Y, Webster R (1999) The surface glycoproteins of $\mathrm{H} 5$ influenza viruses isolated from humans, chickens, and wild aquatic birds have distinguishable properties. J Virol 73:1146-1155

16. Wiley DC, Skehel JJ (1987) The structure and function of the hemagglutinin membrane glycoprotein of influenza virus. Annu Rev Biochem 56:365-394

17. Zhang X, Chen S, Yang D, Wang X, Zhu J, Peng D, Liu X (2015) Role of stem glycans attached to haemagglutinin in the biological characteristics of H5N1 avian influenza virus. J Gen Virol 96:1248-1257

18. Tang Y, Wu P, Peng D, Wang X, Wan H, Zhang P, Long J, Zhang W, Li Y, Wang W, Zhang X, Liu X (2009) Characterization of duck H5N1 influenza viruses with differing pathogenicity in mallard (Anas platyrhynchos) ducks. Avian Pathol 38:457-467

19. Hoffmann E, Neumann G, Kawaoka Y, Hobom G, Webster RG (2000) A DNA transfection system for generation of influenza A virus from eight plasmids. Proc Natl Acad Sci U S A 97:6108-6113

20. Reed LJ, Muench H (1938) a simple method of estimating fifty per cent endpoints. Am J Trop Med Hyg 27:493-497
21. Vigerust DJ, Ulett KB, Boyd KL, Madsen J, Hawgood S, McCullers JA (2007) N-linked glycosylation attenuates H3N2 influenza viruses. J Virol 81:8593-8600

22. Wagner R, WolffT, Herwig A, Pleschka S, Klenk HD (2000) Interdependence of hemagglutinin glycosylation and neuraminidase as regulators of influenza virus growth: a study by reverse genetics. J Virol 74:6316-6323

23. Negovetich NJ, Webster RG (2010) Thermostability of subpopulations of H2N3 influenza virus isolates from mallard ducks. J Virol 84:9369-9376

24. Takahashi T, Kurebayashi Y, Ikeya K, Mizuno T, Fukushima K, Kawamoto H, Kawaoka Y, Suzuki Y, Suzuki T (2010) The low-pH stability discovered in neuraminidase of 1918 pandemic influenza A virus enhances virus replication. PLoS One 5:e15556

25. Chen H, Deng G, Li Z, Tian G, Li Y, Jiao P, Zhang L, Liu Z, Webster RG, Yu $\mathrm{K}$ (2004) The evolution of H5N1 influenza viruses in ducks in southern China. Proc Natl Acad Sci U S A 101:10452-10457

26. Hu J, Hu Z, Song Q, Gu M, Liu X, Wang X, Hu S, Chen C, Liu H, Liu W, Chen S, Peng D, Liu X (2013) The PA-gene-mediated lethal dissemination and excessive innate immune response contribute to the high virulence of H5N1 avian influenza virus in mice. J Virol 87:2660-2672

27. Gao Y, Zhang Y, Shinya K, Deng G, Jiang Y, Li Z, Guan Y, Tian G, Li Y, Shi J, Liu L, Zeng X, Bu Z, Xia X, Kawaoka Y, Chen H (2009) Identification of amino acids in HA and PB2 critical for the transmission of H5N1 avian influenza viruses in a mammalian host. PLoS Pathog 5:e1000709

28. Reddy A, Gibbs BS, Liu YL, Coward JK, Changchien LM, Maley F (1999) Glycosylation of the overlapping sequons in yeast external invertase: effect of amino acid variation on site selectivity in vivo and in vitro. Glycobiology 9:547-555

29. Cueno ME, Imai K, Okamoto T, Ochiai K (2013) Overlapping glycosylation sequon influences the glycosylation pattern of a chimeric protein expressed in tomato leaf and callus. J Biotechnol 164:9-12

30. Tsuchiya E, Sugawara K, Hongo S, Matsuzaki Y, Muraki Y, Nakamura K (2002) Role of overlapping glycosylation sequons in antigenic properties, intracellular transport and biological activities of influenza $\mathrm{A} / \mathrm{H} 2 \mathrm{~N} 2$ virus haemagglutinin. J Gen Virol 83:3067-3074

31. Das SR, Puigbo P, Hensley SE, Hurt DE, Bennink JR, Yewdell JW (2010) Glycosylation focuses sequence variation in the influenza A virus $\mathrm{H} 1$ hemagglutinin globular domain. PLoS Pathog 6:e1001211

32. Sun S, Wang Q, Zhao F, Chen W, Li Z (2011) Glycosylation site alteration in the evolution of influenza A (H1N1) viruses. PLoS One 6:e22844

33. Wei CJ, Boyington JC, Dai K, Houser KV, Pearce MB, Kong WP, Yang ZY, Tumpey TM, Nabel GJ (2010) Cross-neutralization of 1918 and 2009 influenza viruses: role of glycans in viral evolution and vaccine design. Sci Transl Med 2:24ra21

34. Sun X, Jayaraman A, Maniprasad P, Raman R, Houser KV, Pappas C, Zeng H, Sasisekharan R, Katz JM, Tumpey TM (2013) N-linked glycosylation of the hemagglutinin protein influences virulence and antigenicity of the 1918 pandemic and seasonal H1N1 influenza A viruses. J Virol $87: 8756-8766$

\section{Submit your next manuscript to BioMed Central and we will help you at every step:}

- We accept pre-submission inquiries

- Our selector tool helps you to find the most relevant journal

- We provide round the clock customer support

- Convenient online submission

- Thorough peer review

- Inclusion in PubMed and all major indexing services

- Maximum visibility for your research

Submit your manuscript at www.biomedcentral.com/submit 